\title{
ANALYSIS OF TALL BUILDINGS FOR DESIRED ANGLE OF DIAGRIDS
}

\author{
Sree Harsha $\mathbf{J}^{1}$, K Raghu ${ }^{2}$, G Narayana ${ }^{3}$ \\ ${ }^{1}$ Post graduate student, Dept of Civil Engineering, SJCIT, Chickballapura, Karnataka, India \\ ${ }^{2}$ Assistant professor, Dept of Civil Engineering, SJCIT, Chickballapura, Karnataka, India \\ ${ }^{3}$ Head of the department, Dept of Civil Engineering, SJCIT, Chickballapura, Karnataka, India
}

\begin{abstract}
Diagrids structural systems have emerged as most innovative way of approach to tall buildings in this era. Variations of the diagrid system have evolved to the point of making its use to construction of tall building. Investigation in depth on design methodology of Diagrids structures, gave the powerful structural strength and symbolic architectural view. The diagrid structure of each storey height is designed with diagonals placed at various uniform angles as well as gradually changing angles along the building height in order to determine the optimal uniform angle for each structure with a different height and to investigate the structural potential of diagrids with changing angles The comparison of 24-storey diagrid structural system with different uniform angles is presented here.. The 24 storey diagrid structural system with different angles are modelled and analyzed by using Etabs Software. Now a day the Non linear analysis is essential for a tall building, in this present study the non linear analysis is carried out for the considered diagrid structural system. The comparison of analyzed results in terms of top storey displacement, time period, storey shears and mode shapes is presented here.
\end{abstract}

Keywords: Angle of Diagrids, Displacement, Mode Shapes, Time Period, Storey shear, P delta etc...

\section{INTRODUCTION}

Diagrids means diagonally placed grids. In present day the faster growth of population and scarcity of available land, the taller structures are preferable now a days. So when the height of structure increases then the lateral load is very much important. For that the lateral load resisting system becomes more important than the structural system that resists the gravity loads. The lateral load resisting systems that are widely used are rigid frame, shear wall, wall frame, braced tube system, outrigger system and tubular system. Now a day the diagrid - diagonal grid structural system is widely used for tall buildings due to its structural efficiency and aesthetic potential provided by the unique geometric configuration of the system. The structural and architectural design of diagrid buildings falls cleanly between the typical education or experience of the architect and engineer. The design of the structural stability system of early tall buildings was clearly the job of the Engineer. Architects responded with facade designs that reflected trends of the period. Hence the diagrid, for structural effectiveness and aesthetics has generated renewed interest from architectural and structural designers of tall buildings. So, when the diagrid structural system is provided in tall building, there is a very much important of angle of diagrid, the questions are arises in our mind that, which should be the desire angle of diagrid So, to evaluate these problems, the present work is carried out using different angle by considering different storey module. The analysis is done using Etabs 2013 software. The results are discussed in terms of displacements, time period and mode shapes by considering static and dynamic properties.
In the present work four different models are considered which are having different angle of inclination i.e. $50.2^{\circ}$, $67.4^{\circ}, 74.5^{\circ}$ and $82.1^{\circ}$ which are represented by letter A, B, $\mathrm{C}$, and $\mathrm{D}$ respectively. The building dimension used is $36 \mathrm{mX} 36 \mathrm{~m}$ and total height of the building is $86.4 \mathrm{~m}$. The below figure 1 shows the typical plan of the building

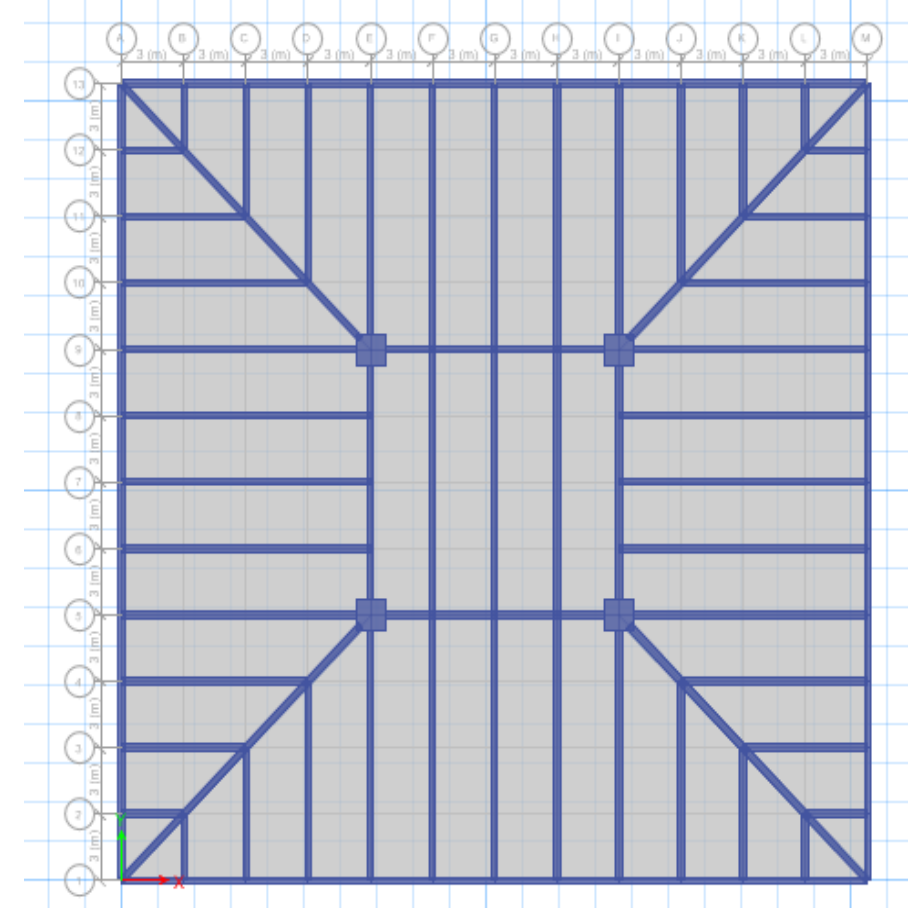

Fig -1: Plan view of all models 


\section{MODEL DESCRIPTION}

These are the geometric and structural details of the models are as follows.

i. Plan dimensions:36m X 36m

ii. Slab thickness : $140 \mathrm{~mm}$

iii. Typical storey height $: 3.6 \mathrm{~m}$

iv. Strength of concrete : $40 \mathrm{Mpa}$

v. Strength of steel :500 Mpa

vi. Beam of sizes :300mm X $600 \mathrm{~mm}$ and $300 \mathrm{mmX}$ $1050 \mathrm{~mm}$

vii. Diagrids of size :500mm X 500mm

viii. Column of Size: $1.4 \mathrm{~m} \mathrm{X} 1.4 \mathrm{~m}$

The four different storey module is shown in below figure 2

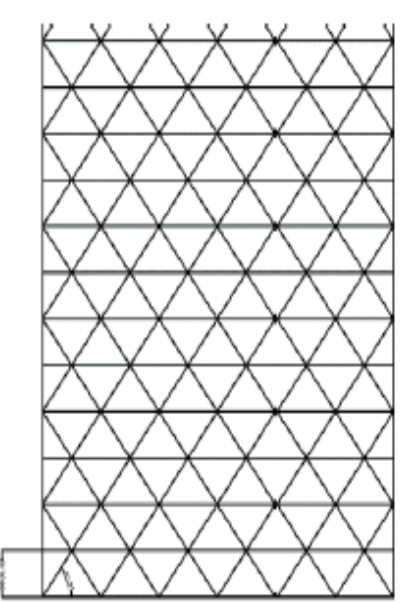

(a)

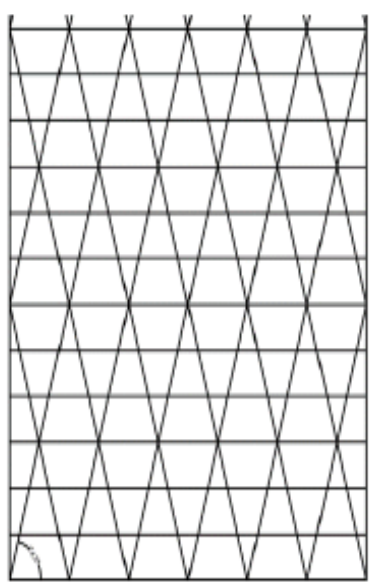

(c) 6 Storey module

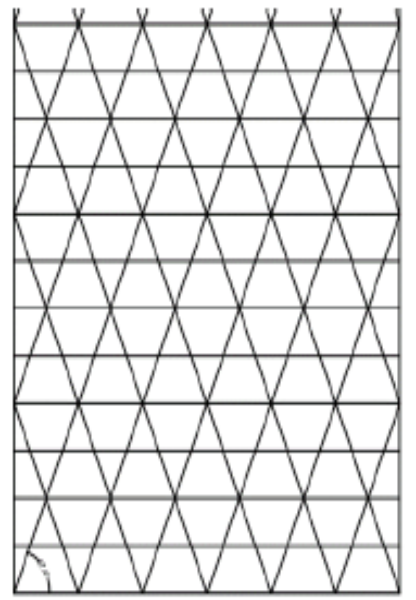

(b) 4 Storey module

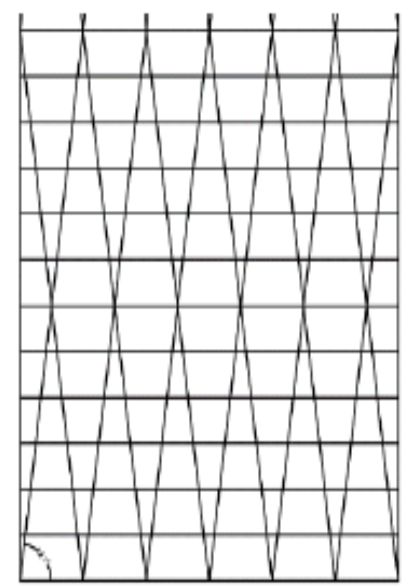

(d) 12 Storey module
Fig -2: Different storey module

The design dead load and live load is considered as per IS 875 Part I and Part II respectively. The design earthquake load is computed based on the zone factor 0.16 , soil type II, Importance factor 1, Response Reduction 5 as per IS-18932002. The design wind load is computed based on location Bangalore, Wind speed $33 \mathrm{~m} / \mathrm{s}$, Terrain category 2, Structure class B, Risk Coefficient 1, Topography factor 1 as per IS 875 Part III. Modelling, analysis and design of diagrid structure are carried out using ETABS 2013 software. The end condition for diagrid is assumed as hinged. The support conditions are assumed as fixed.

\section{ANALYSIS RESULT}

Here, the dynamic analysis results for all models in terms of displacement, storey shears and time period are represented separately in $\mathrm{X}$ and $\mathrm{Y}$ directions.

\subsection{Displacement Results}

The displacement results for Model-A, Model-B, Model-C and Model-D in $\mathrm{X}$ and $\mathrm{Y}$ directions by considering response spectrum analysis is as shown in Figure 3, Figure 4, Figure 5, Figure 6, Figure 7, Figure 8, Figure9 and Figure 10.

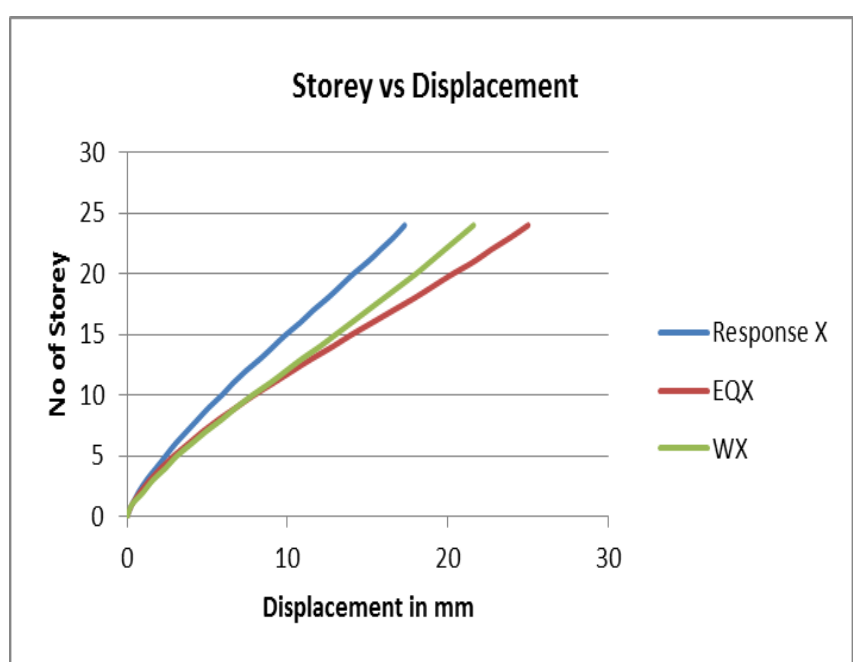

Fig -3: Displacement results For Model A in X direction

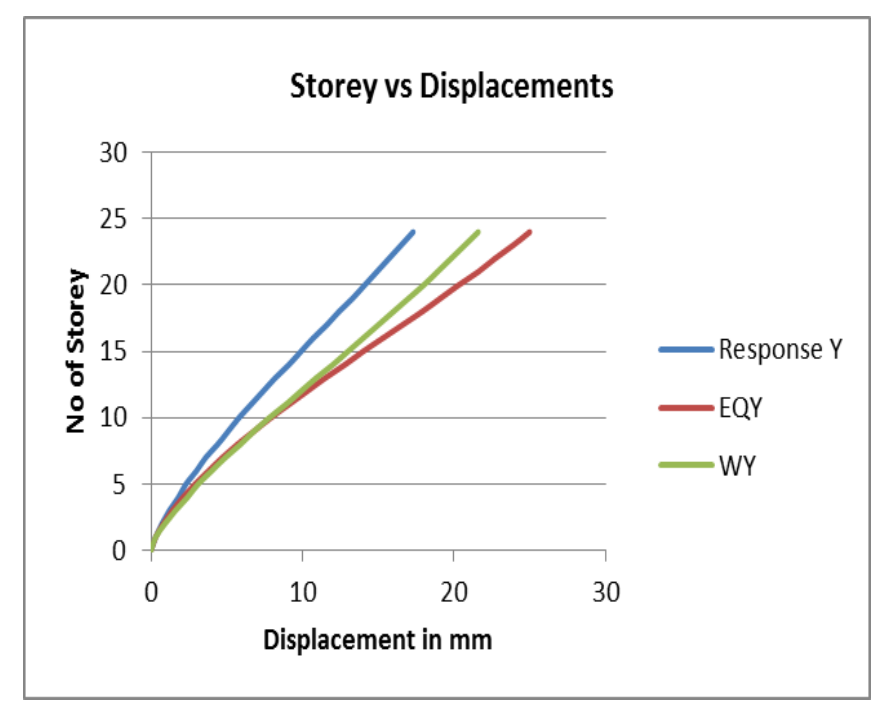

Fig -4: Displacement results For Model A in Y direction 


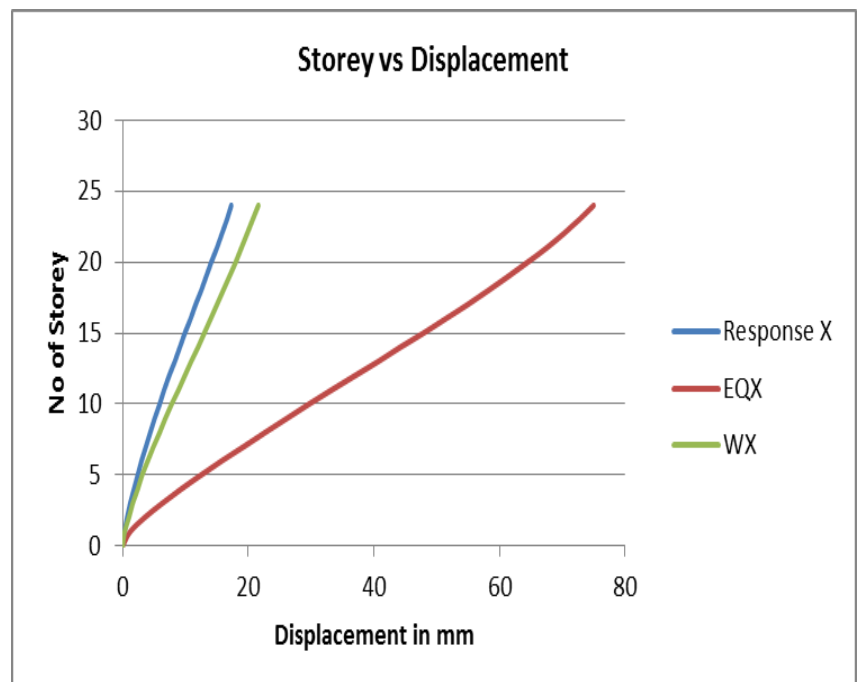

Fig -5: Displacement results For Model B in X direction

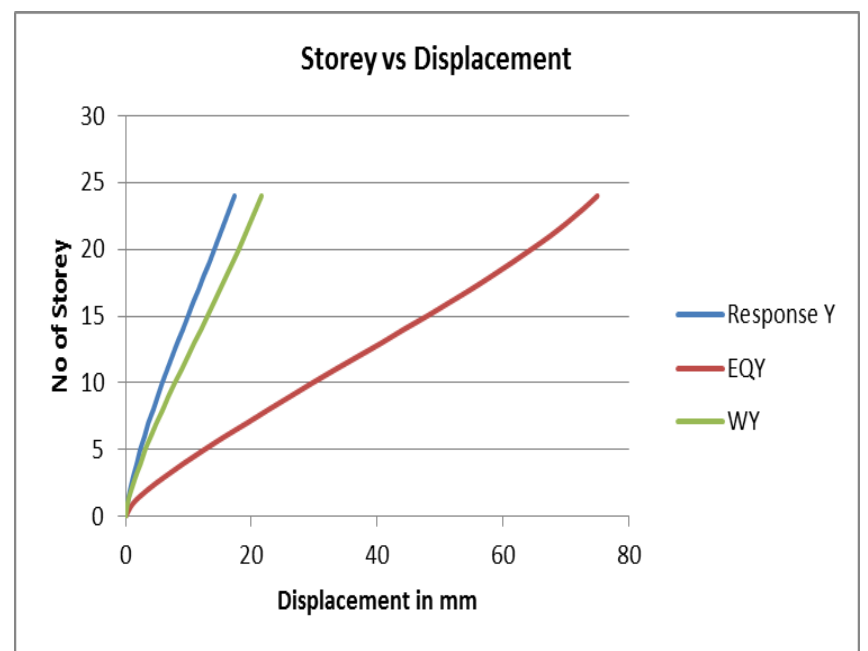

Fig -6: Displacement results For Model B in Y direction

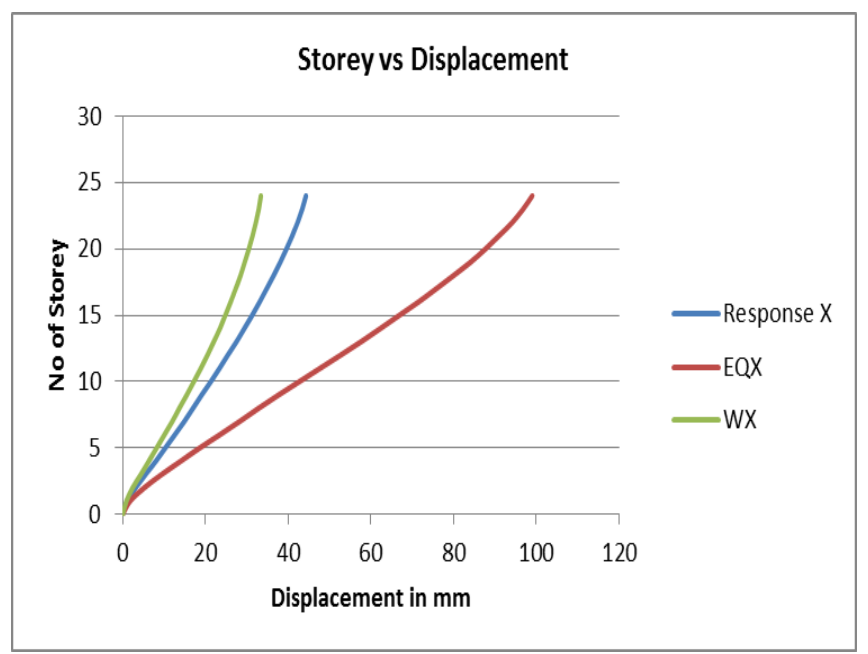

Fig -7: Displacement results For Model C in X direction

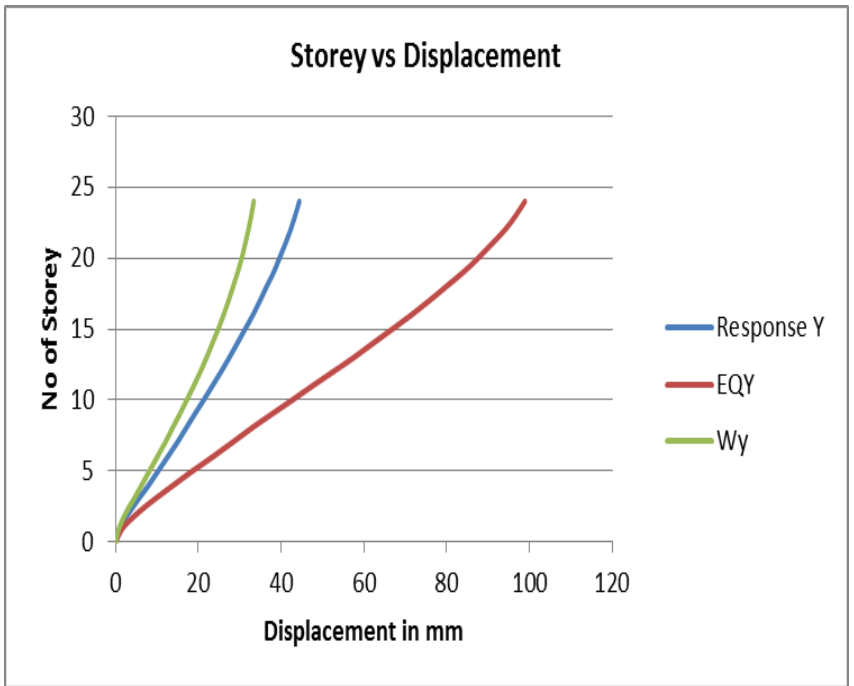

Fig -8: Displacement results For Model C in Y direction

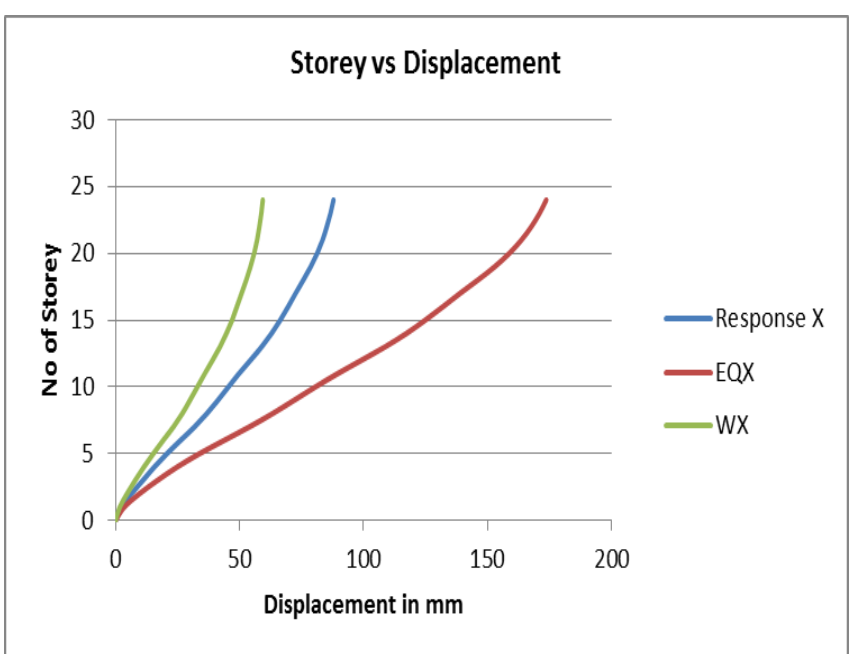

Fig -9: Displacement results For Model D in X direction

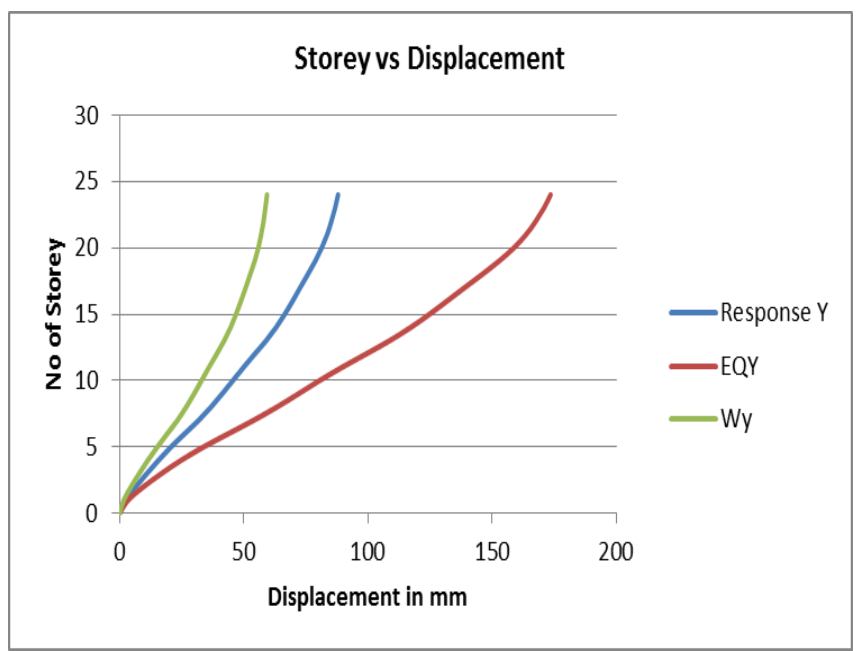

Fig -10: Displacement results For Model D in Y direction

From the above figures i.e. Fig 3 to Fig 10, we can notice that, the displacement results are within the limits as per IS code. 


\subsection{Time Period}

By doing non linear analysis, time period is found out by considering 30 mode shapes for higher accuracy. By doing analysis without considering the $\mathrm{p}$-delta effects we will get one set of values and after considering the p-delta effect we will another set of values. The same variations are shown in graphs below.

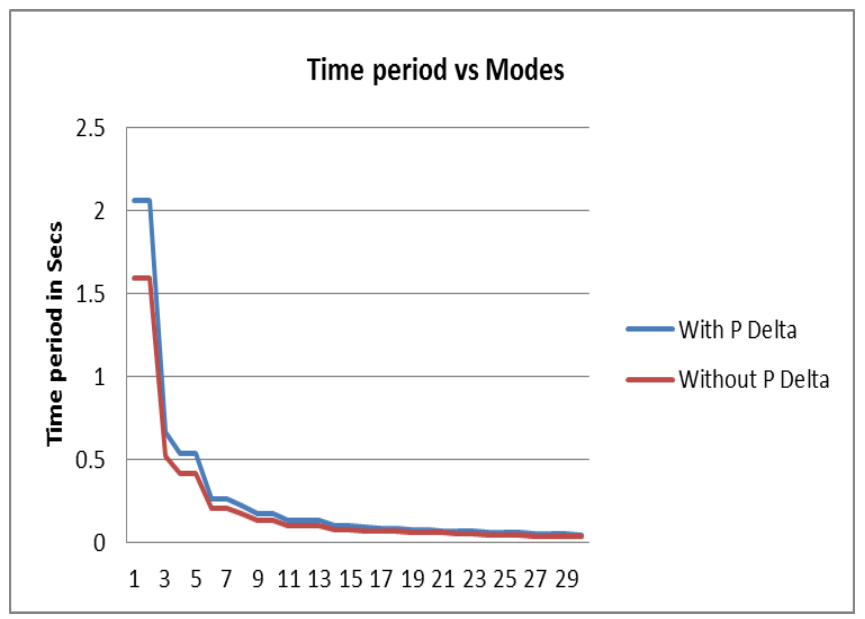

Fig -11: Time Period for Model A

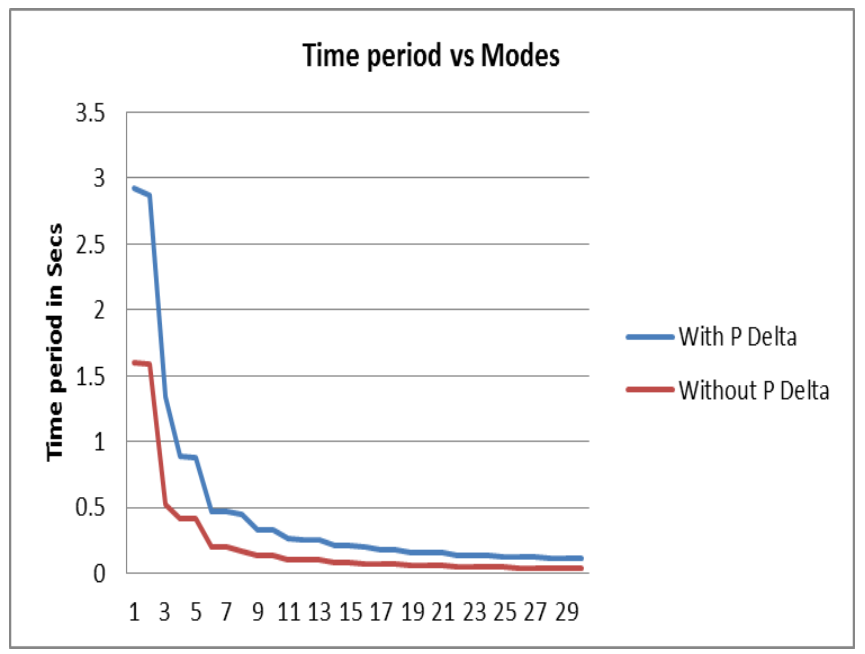

Fig -12: Time Period for Model B

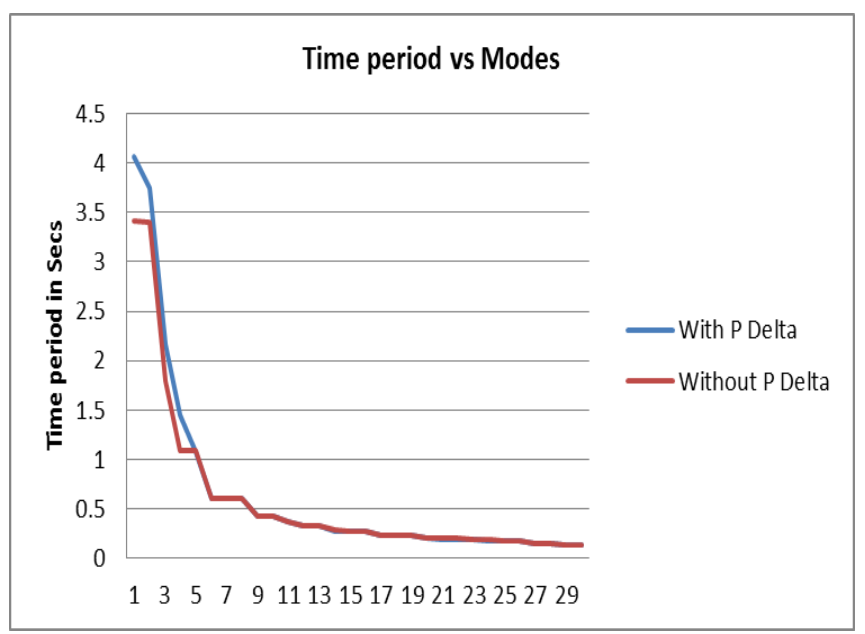

Fig -13: Time Period for Model C

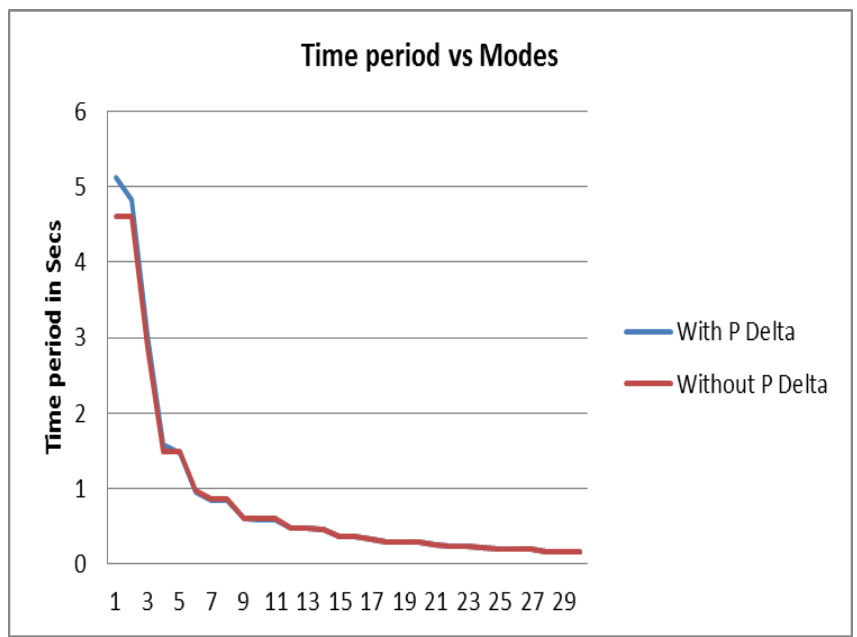

Fig -14: Time Period for Model D

From the above graphs we can clearly see that if we include p-delta effects the time period is going to change.

\subsection{Storey Shear}

The storey shear results are presented in Figure 15 for all the models for earthquake load. Due to symmetry in building the storey shear are same in both directions.

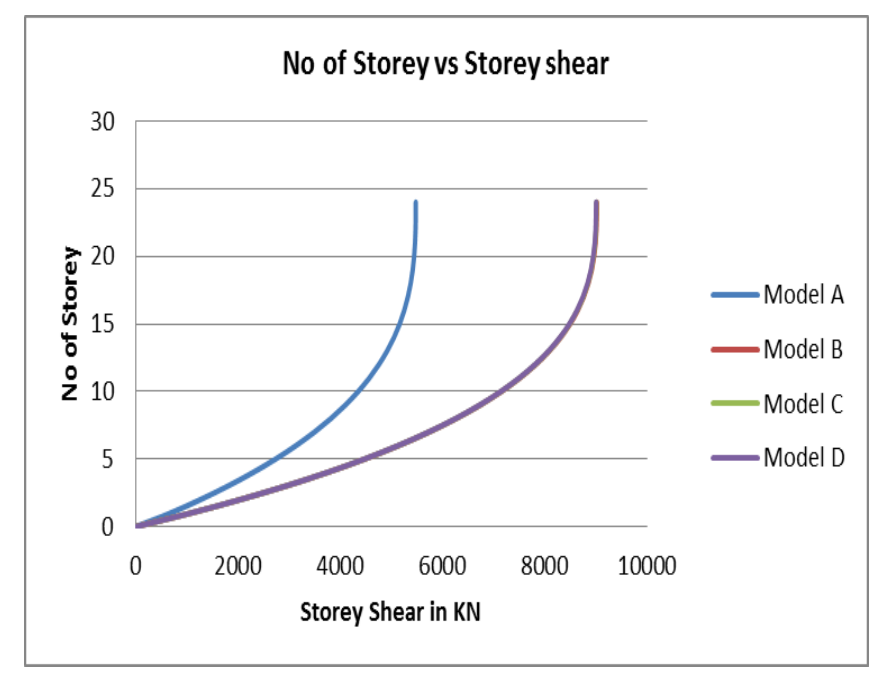

Fig -15: Storey shears for all Models

From above the graph the values of Model A is half then the values of Model B, Model C and Model D. Then storey shear of model B, C and D are having same values that why curves are going to overlap on one other.

\section{CONCLUSION}

From the above results it is observed that desire angle is in the range of 60 to 80 degree. Diagrid structural system provides more flexibility in planning interior space and facade of the building. From the dynamic analysis, it is concluded that the displacement of different angles of diagrids are within the permissible limits. From the above results, we can observe that the dynamic parameters are going to change when p-delta analysis is performed. 


\section{ACKNOWLEDGEMENTS}

I am thankful to my guide Mr. Raghu K and Dr. G Narayana for their guidance and also thankful to department civil engineering S J C Institute of technology, chickaballapur. Thanks to my dear friends who have supported me to complete this work.

\section{REFERENCES}

[1] Kyoung S. Moon, Jerome J. Connor and John E. Fernandez, "Diagrid Structural Systems for Tall Building: Characteristics and Methodology for Preliminary Design", Willey Interscience Publication.

[2] Khushbu Jani and Paresh V. Patel, "Design of Diagrid Structural System for High Rise Buildings as Per Indian Standards", Structures Congress 2013, ASCE 2013

[3] Khushbu Jani and Paresh V. Patel, "Analysis and Design of Diagrid Structural System for High Rise Steel Buildings", Published by Elesevier Ltd.

[4] Mir M. Ali and Kyoung S. Moon, "Structural Developments in Tall Buildings: Current Trends and Future Prospects", Architectural Science Review Vol 50.3, pp 205-223.

[5] Nishith B. Panchal, Vinubhai R. Patel, "Diagrid Structural System: Strategies to Reduce Lateral Forces on High-Rise Buildings", International Journal of Research in Engineering and Technology, Volume: 03, Issue: 03, April-2014. pp. 374-378

[6] Nishith B. Panchal, Dr. V. R. Patel, Dr. I. I. Pandya "Optimum Angle of Diagrid Structural System" International Journal of Engineering and Technical Research (IJETR) ISSN: 2321-0869, Volume-2, Issue-6, June 2014

[7] IS: 456-2000. Plain and Reinforced Concrete- Code of Practice (Fourth Revision), Bureau of Indian Standard, New Delhi.

[8] IS: 1893(Part-I)-2002, Criteria for Earthquake Resistant Design of Structures, Bureau of Indian Standard, New Delhi.

[9] IS:875(Part-I, II, III)-1987, Code of Practice for Design Loads (other than Earthquake) for Buildings and Structures, Bureau of Indian Standard, New Delhi.

\section{BIOGRAPHIES}

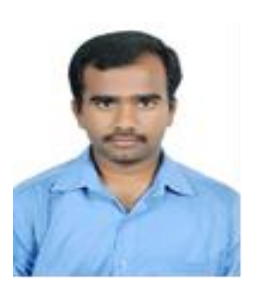

I am Mr. Sree Harsha J I am pursuing my masters of technology in structural engineering from $\mathrm{S} J \mathrm{C}$ Institute of Technology, Chickaballapur. I am doing my dissertation work under the Guidance of Mr. K Raghu. I have pursued my B E, civil engineering from U.V.C.E, Bangalore University, Bangalore

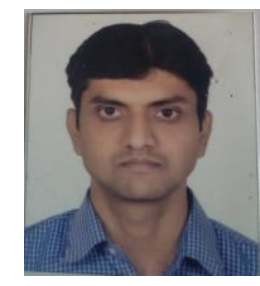

He is Mr. K Raghu Assistant Professor, Department of civil engineering, S J C Institute of Technology, Chickaballapur. $\mathrm{He}$ is also a structural Design consultant. He has more than 6 years of experience in the field of structural and civil engineering. He has more than 3 years of teaching Experience. He has designed various projects which includes steel structures and High rise buildings.

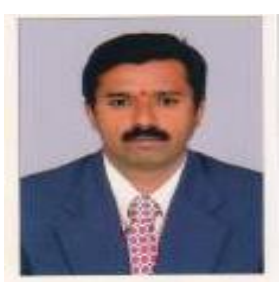

He Mr. DR. G Narayana, Professor and Head of Department, Department Of Civil Engineering, S J C Institute of Technology, Chickaballapur. He has a wide experience in teaching and research in the field of Structural engineering. He is also a structural designed consultant for many projects. 